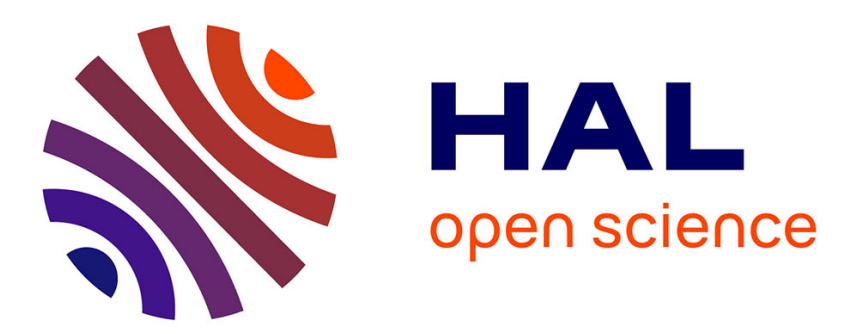

\title{
Folded Multilayer C-Sections With Large Group Delay Swing for Passive Chipless RFID Applications
}

Raji Sasidharan Nair, Etienne Perret

\section{To cite this version:}

Raji Sasidharan Nair, Etienne Perret. Folded Multilayer C-Sections With Large Group Delay Swing for Passive Chipless RFID Applications. IEEE Transactions on Microwave Theory and Techniques, 2016, 64 (12), pp.4298-4311. 10.1109/TMTT.2016.2613049 . hal-02066603

\section{HAL Id: hal-02066603 https://hal.science/hal-02066603}

Submitted on 1 Jul 2020

HAL is a multi-disciplinary open access archive for the deposit and dissemination of scientific research documents, whether they are published or not. The documents may come from teaching and research institutions in France or abroad, or from public or private research centers.
L'archive ouverte pluridisciplinaire $\mathbf{H A L}$, est destinée au dépôt et à la diffusion de documents scientifiques de niveau recherche, publiés ou non, émanant des établissements d'enseignement et de recherche français ou étrangers, des laboratoires publics ou privés. 


\title{
Folded Multilayer C-Sections with Large Group Delay Swing for Passive Chipless RFID Applications
}

\author{
Raji Sasidharan Nair, Member IEEE, Etienne Perret, Senior Member, IEEE, and Smail Tedjini, Senior \\ Member, IEEE
}

\begin{abstract}
An origami based multilayer structure suitable for passive chipless Radio Frequency Identification (RFID) applications is presented in this article. Contrary to the existing multilayer designs where metallic via is used for the interconnections, the proposed technique uses the folding of the structure designed in a flexible substrate. Thus, the multilayer structure is obtained from a thin printed circuit board that is folded to give the desired 3D structure. The proposed structure consists of cascaded commensurate transmission line sections (also known as $\mathrm{C}$-sections) coupled at alternative ends. The group delay characteristic of the $\mathrm{C}$-sections is utilized for encoding. Broad side coupling of the structure is exploited here, which enables large group delay with higher frequency selectivity. It is proved that to produce the same amount of delay, linearly cascaded $\mathrm{C}$-sections demands five times more number of $\mathrm{C}$ sections than that of a multilayered structure, which also signifies the factor of miniaturization of the proposed design. A coding capacity of 6 bits and 12 bits are estimated, respectively, for single and multi-group of multilayered $\mathrm{C}$-sections in the allowed industrial, scientific and medical (ISM) bands. This shows for the first time that frequency domain chipless technology can be compatible with the use of ISM bands. It also allows a coding capacity of 43 bits in the ultra-wideband (UWB) band which is comparable with the EAN 13 barcode.
\end{abstract}

Index Terms - C-sections, cascaded transmission line, chipless RFID, folding technique, group delay, multilayer RF device, RF identification.

\section{INTRODUCTION}

$\mathrm{M}$ ODERN microwave and wireless communication systems need more compact design structures. Presently Low-Temperature Co-fired Ceramic (LTCC) technology is most popular because of its advantages such as threedimensional structure, high integrity, and compact size [1], [2]. Literature provides various designs of microwave filters using LTCC technology [3], [4]. These technologies pose new problems and, in particular, require efficient novel vertical transitions interconnecting the layers with maximum bandwidth and minimum insertion loss. Most of the vertical transitions in planar circuits reported to date in the literature

This study is financially supported by the French National Research Agency via ANR-09-VERS-013 program.

The authors are with LCIS, University of Grenoble Alpes, 50 rue Barthélémy de Laffemas - BP 54, 26902, Valence Cedex 9 - France. Etienne Perret is also with the Institut Universitaire de France. (email: rajisasidharannair@yahoo.co.in,_ etienne.perret@1cis.grenoble-inp.fr, smail.tedjini@lcis.grenoble-inp.fr.). Raji Sasidharan Nair is currently with Masdar Institute of Technology, Abu Dhabi, United Arab Emirates. can be classified in the following two main categories: aperture-coupled transitions [5], [6] and transitions based on the use of a single via hole [7]-[9]. However, these approaches are complex, expensive, and much too costly to be used for chipless Radio Frequency Identification (RFID) tags [10]. The cost of the chipless tags is a critical factor; in most cases, its price is much lower than the RFID tags. Besides, as efficient chipless tags are expected to be manufactured, studies on the technical achievements of low cost complex devices such as multilayer circuits must be conducted.

This article proposes a folding technique such that a multilayer structure is formed without any metallic interconnections such as via. The multilayer structure is obtained from a thin flexible printed circuit board, which is folded. The desired structure can be achieved by a combination of the printed patterns and the manner in which the flat surface is folded. This realization process is a kind of origami that, for example, has been utilized to realize frequency-selective surfaces [11], or to achieve anti-theft tags based on low frequency LC-resonant structure [12]. [11] prompted to a very general principle that an $\mathrm{RF}(3 \mathrm{D})$ structure can be made from a folded flat structure. However, the folding technique presented here is different from [11] particularly because of the presence of the proposed multilayer structure which is equivalent to a structure with via (LTCC structures).

In this article, the design consists of cascaded commensurate $\mathrm{C}$-sections, and the objective is to realize high preferment chipless tags that can be compatible with the ISM band. This is a challenging task, because till date, the order of magnitude of the number of bits that can be encoded in chipless is rather 10 per $\mathrm{GHz}$, which is totally incompatible with the ISM bands [10], [13], [14]. In this article, we present a tag design able to encode several bits in the $100 \mathrm{MHz}$ ISM frequency band. This significant improvement is primarily based on an important technological breakthrough linked to the use of folded $\mathrm{C}$-sections as described in Fig. 1. Indeed numerous chipless tag topologies can be seen in the literature. These tags can be broken down into two categories: one based on the association of antennas and a "filter" for the coding part of the information [15], and the other based solely on a unitary object or "RF encoding particles" (REP) that can intrinsically have a characteristic radar signature [10], [16]. In this article, the introduced tag belongs to the first category. A comparison of different chipless RFID tags [13], [17]-[23] are tabulated in Table I. The table provides information such as the density of coding per frequency (DPF), the tag's dimension, or even the 


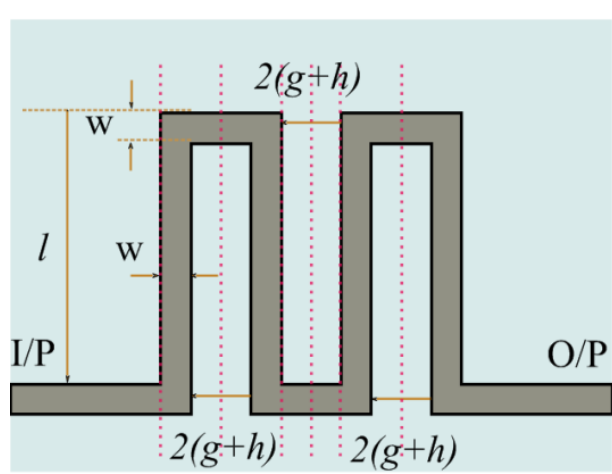

(a)

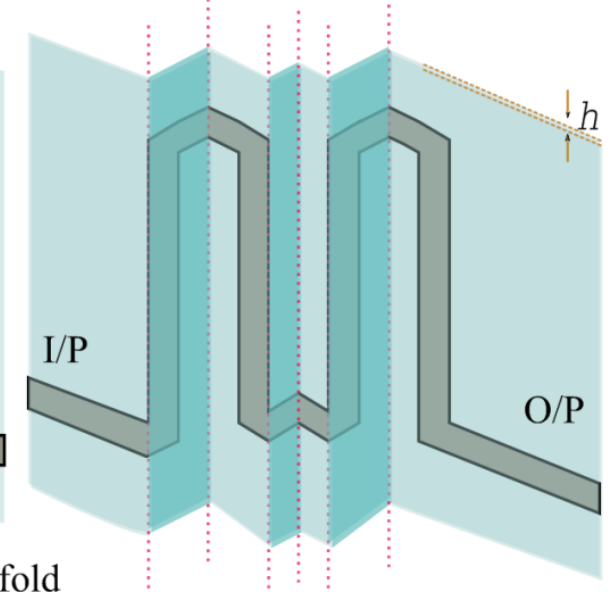

(b)

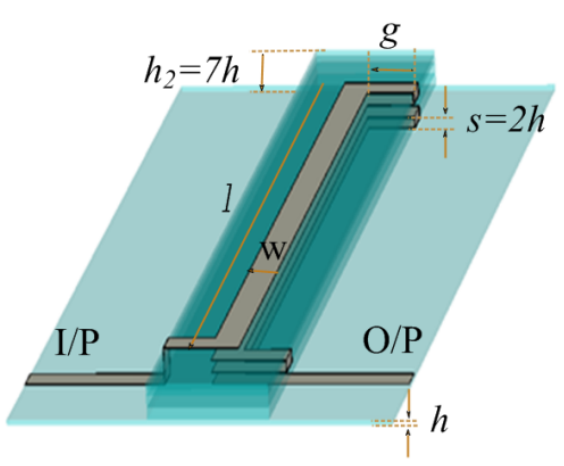

(c)

Fig. 1. The structure explains the method of folding and the folded multilayer design, in this case, one group of 2 folded C-sections. (a) $2 \mathrm{D}$ planar pattern before folding, with fold at each dash line (in red) with different design parameters; the gray parts are conductive parts that are made on a substrate of thickness $h=s / 2$ fold. (b) The flexible pattern is being folded lengthwise along the dash line. (c) The folded multilayer C-section. For better visibility, the ground plane and the dielectric substrate have been hidden.

coding capacity. The advantage of the proposed approach is the level of compromise between the number of bit and the necessary bandwidth (DPF in bits / GHz). Indeed, for the first time it allows obtaining a tag with an amount of more than 10 bits information while being compatible with the ISM frequencies.

The authors have already proved the concept of using linearly cascaded $\mathrm{C}$-sections in chipless RFID applications [24]-[26], that is, how to realize a tag composed of two antennas where the coding circuit, that is the "filter" part, is realized with $\mathrm{C}$-sections. Hence, in this article, the authors mostly concentrated on the coding circuit, which in such configurations, is the core of the chipless tag. We will see that the broadside coupling of the multilayer structure enables larger group delay (GD) and high selectivity, which, in turn, permits increasing the coding capacity. Multilayer C-sections also have advantages such as circuit miniaturization and hence compactness [4], [27], [28]. The authors were inspired from the structure proposed in [4] which enables much larger ratio of GD swing to the frequency bandwidth because of the multilayer design in comparison to the linear $\mathrm{C}$-sections. It offers more compact structure and permits a size reduction factor of 7 in comparison to the linear C-section. However, like all other multilayer structures, this structure is also based on LTCC technology and metallic via are used for interconnections. Unlike [4] where the objective was to obtain a negative linear GD slope for analog signal processing applications, the idea here is to create a new generation of chipless tag, that is, very frequency-selective devices with very low cost. This is why a novel and cost-effective fabrication process has been developed and tested for the production of these chipless tags. This approach is very flexible and allows to easily set the number of layers and their thickness without complicating the manufacturing process technology. Thus, the number of layers can be simply increased by changing the number of the folds done on the initial plate structure. Similarly, the thickness of the layers is simply related to the thickness of the substrate chosen. It is interesting to note that this approach is consistent with the use of paper materials, printed by flexography technique [29], which makes it very cost effective. The folding process from the paper industry perfectly suits the mass production of chipless RFID tags. With paper or plastic film, it is possible to simply obtain thicknesses of a few tens of microns, which is comparable to or even lower than those conventionally used in LTCC technology (layers of $100 \mu \mathrm{m}$ are used in [4]). This

TABLE I

COMPARISON OF DIFFERENT CHIPLESS RFID TAGS

\begin{tabular}{|c|c|c|c|c|c|c|c|}
\hline Ref. & $\begin{array}{l}\text { Dimension of } \\
\text { the tag }\left(\mathrm{cm}^{2}\right)\end{array}$ & $\begin{array}{l}\text { Coding } \\
\text { Capacity } \\
\text { (bits) } \\
\end{array}$ & $\begin{array}{c}\text { Freq. of operation } \\
\text { / Freq. range } \\
\text { (GHz) }\end{array}$ & $\begin{array}{c}\mathrm{DPF} \\
\text { (bits/GHz) }\end{array}$ & $\begin{array}{c}\text { Freq. } \\
\text { Regulation }\end{array}$ & Coding Technique & Resonator Type \\
\hline [17] & $\begin{array}{c}9.5 \cdot 4.9 \text { (without } \\
\text { antennas) }\end{array}$ & 8 & $0-6 / 6$ & 1.3 & UWB & Time Domain & Tapered microstrip line \\
\hline [18] & $3.6 \cdot 2.8$ & 5 & $5.475-6 / 0.525$ & 9.5 & UWB & Freq. Domain & Dipole (REP) \\
\hline [19] & $8.8 \cdot 6.5$ & 35 & $3.1-10.6 / 7.5$ & 4.6 & UWB & Freq. Domain & Spiral \\
\hline [13] & $7 \cdot 2.5$ & 20 & $2-4 / 2$ & 10 & Not compliant & Freq. Domain & Slot (REP) \\
\hline [20] & $2 \cdot 1.5$ & 9 & $2-5.5 / 3.5$ & 2.5 & Not compliant & Freq. Domain & C-shape (REP) \\
\hline [22] & $4 \cdot 4$ & 49 & $3.1-10.6 / 7.5$ & 6.5 & UWB & Freq. Domain & Circle (REP) \\
\hline [23] & $4 \cdot 2.5$ & 41 & $3.1-10.6 / 7.5$ & 5.5 & UWB & Freq. Dual Band & Stepped impedance (REP) \\
\hline $\begin{array}{l}\text { Proposed } \\
\text { tag }\end{array}$ & $10 \cdot 5.5$ & $\begin{array}{c}12.05 \text { (ISM) } \\
43.27 \text { (UWB) }\end{array}$ & $\begin{array}{c}2.45 \text { and } 5.8 / 0.1 \\
\text { and } 0.15 \\
3.1-10.66 / 7.5 \\
\end{array}$ & $\begin{array}{l}48.2 \\
5.8\end{array}$ & ISM \& UWB & $\begin{array}{l}\text { Time Domain \& } \\
\text { Freq. Domain }\end{array}$ & C-section \\
\hline
\end{tabular}




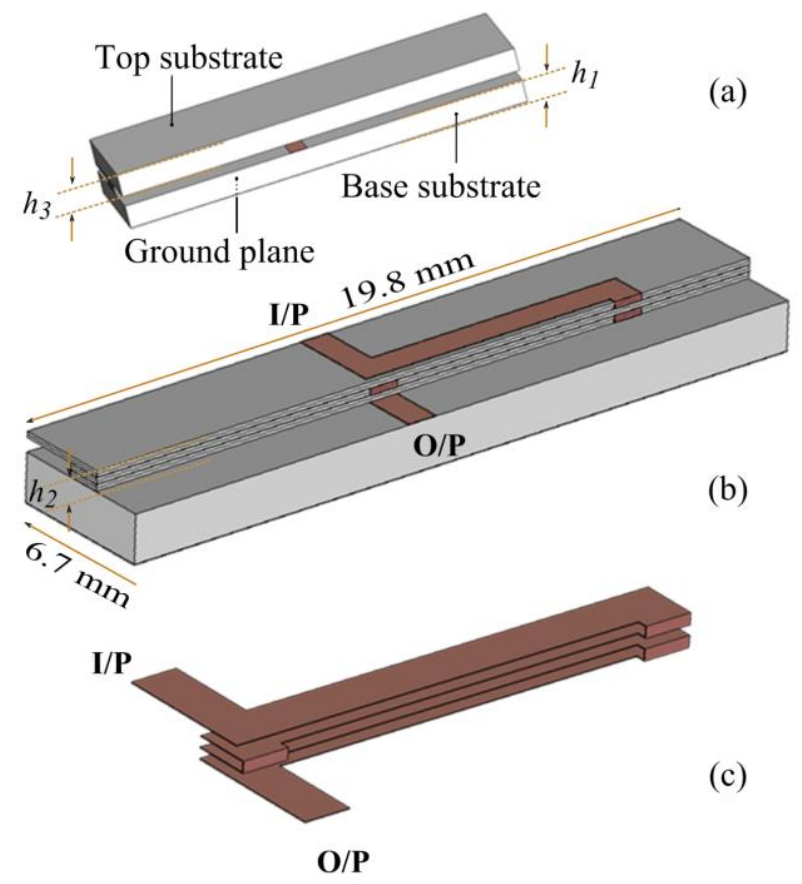

Fig. 2. Simulated structure of the folded multilayer design (one group of 2 folded C-sections): (a) top view with top and bottom substrates, (b) cross sectional view, without the top substrate, (c) structure of the folded C-section without substrates, and with the tow port used for the simulation. Two Csections are folded here. The structure has a dimension of $6.7 \cdot 19.8 \mathrm{~mm}^{2}$.

versatile fabrication process takes advantage here for producing $\mathrm{C}$-sections where the surface coupling involving very small gaps allow achieving very frequency-selective structures with significant GD. It is based on the principle that such structures allow to encode a large number of data on frequency bands of several tens of MHz.

\section{Prototype Design}

The proposed multilayer $\mathrm{C}$-section fabrication process is shown in Fig. 1. The device is created by folding an initial planar pattern at each particular point as explained in Fig. 1 (a) and (b). In the case of the multilayer C-section, this planar pattern looks similar to a meandering line. It is previously designed so that when folded, the multilayer C-section is obtained. It is realized on a thin dielectric subtract of thickness $h$. The corresponding folded design is shown in Fig. 1 (c). As

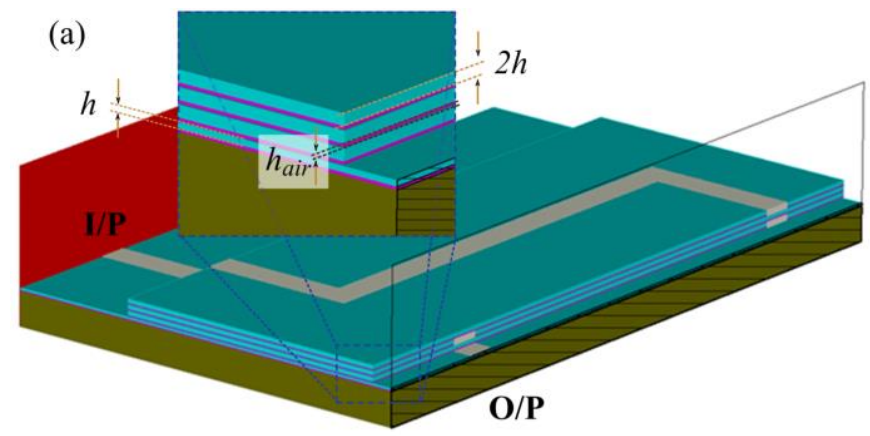

(b)

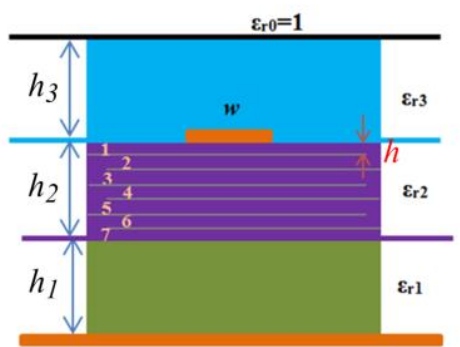

Fig. 3. (a) Simulated structure of the folded multilayer design with the air gaps of thickness $h_{\text {air }}$. (b) The multilayer structure proposed in [27], [31] to calculate the effective permittivity $\varepsilon_{\text {reff }}$ is used in (1) for the multilayer Csection.

explained in Fig. 1, the initial planar pattern is folded in a particular manner to fabricate the multilayer design. This is an original method of realization to obtain the multilayer structures comprising metal connections between the different layers. Various design parameters are shown in the figure, where $g$ is the spacing between the meander lines that make up the initial planar pattern, $l$ is the length, and $w$ the width of the $\mathrm{C}$-section. Then, $s$ is the thickness of each layer of the final structure (which is twice the thickness of the dielectric: $s=2 h$ ). The advantage of this technique is that to get to another but comparable structure there is a large number of ways to fold the planar structure. This is also why other structures can easily be obtained from such an approach. For example, if one wishes for manufacturing purposes, increase the structure's dimensions (to impose a minimum spacing between two folds, for example), simply change the starting planar structure so that after folding it, $g$ increases the size and reduces the length $l$ (to keep the same frequency reasoning, it is sufficient to have the constant $g$ ).

Simulation has been done for the folded multilayer Csection design using CST Microwave Studio. CST allows use


Fig. 4. Simulated structure of the folded multi-layer design with different air gap thickness $h_{\text {air }}$. (a) $\mathrm{S}_{21}$, (b) $\mathrm{S}_{11}, \mathrm{~S}_{21}$, and (c) group delay observed for different values of $h_{\text {air }}$ - the simulated structure is the one presented Fig. $2 ; l=11.4 \mathrm{~mm} \varepsilon_{r l}=\varepsilon_{r 3}=3.55, \varepsilon_{r 2}=3.25, \tan \delta 1=\tan \delta 3=0.0027$ and $\tan \delta 2=0.005, h_{l}=h_{3}=0.8 \mathrm{~mm}, h=50 \mu \mathrm{m}$, $g=3 \mathrm{~mm}, w=0.7 \mathrm{~mm}$. 

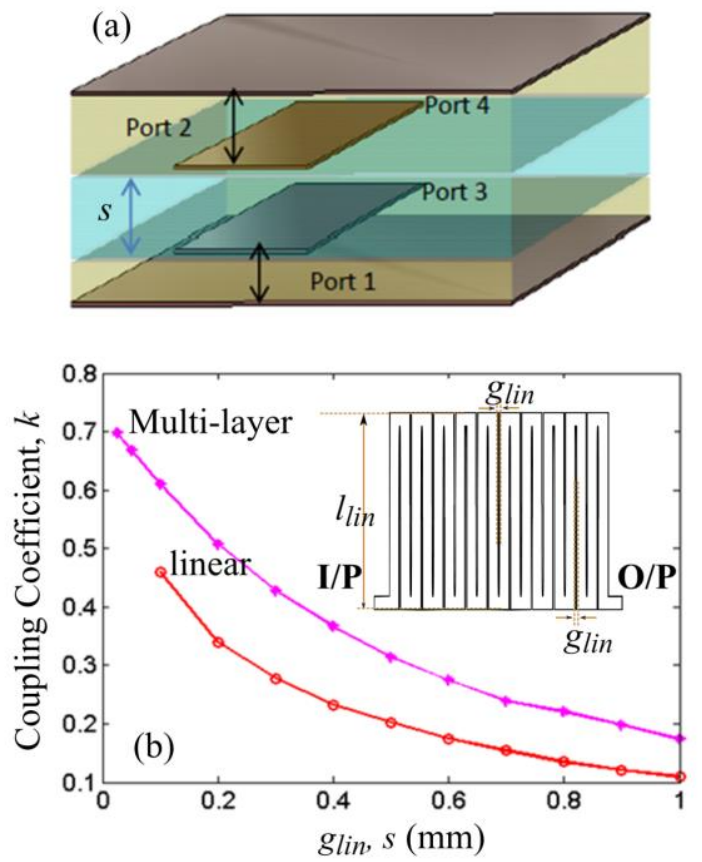

Fig. 5. The multilayer structure simulated in HFSS to calculate the coupling coefficient $k$. (a) Designed multilayer structure. The structure is designed as stripline to correctly assign the ports in simulation. (b) Corresponding $k$ for linear and multilayer lines.

of Resonant Fast S-parameter solver set up in the frequency domain solver, which enables fast computation time for highly resonant multilayer designs. As explained in [24], [25], [30], for classical planar C-section, a direct expression can be used to link the length $l$ and the frequency where the GD is maximum. Indeed, each $\mathrm{C}$-section group is able to produce a GD peak at $\mathrm{F}(l)$, where

$$
F(l) \approx \frac{c}{4 l \sqrt{\varepsilon_{\text {reff }}}}
$$

where $\varepsilon_{\text {reff }}$ is the effective permittivity of the multilayer structure and $c$ the light velocity. This expression will also be used here to obtain a first approximation in the case of the multilayer configuration. Later, the lengths are optimized using simulation.

Once the flexible substrate structure is folded [Fig. 1 (c)], the multilayer design is sandwiched between two substrates [see Fig. 2 (a)]. This encapsulation using base and top substrates ensures the rigidity of the structure, and facilitates reproducibility. By this approach, it is possible to press the folded multilayer device to remove or to control air gaps that may be present. The structure of the folded multilayer design with air gaps is shown in Fig. 3 (a). These air layers, which are difficult to remove in practice, play an important role. Indeed, as shown in Fig. 4, the thickness of these air layers $h_{\text {air }}$ controls the S-parameters of the structure. A significant difference between with and without the air layers can be seen at the frequency where the GD is important (horizontal dashed lines in Fig. 4). The same observation can be done concerning the impact on the thickness of the flexible dielectric $h$ (not presented here). Thus, it is possible to move from a structure with a classic C-section behavior [25], [30] (with air gaps and low thickness $h$ ) to a notch filter (without air gaps and high thickness $h$ ). For a chipless intended application, the structure having air gaps is therefore preferred, and air layer



Fig. 6. Comparison between two folded multi-layer C-sections and ten linear cascaded C-sections; for linear C-section: $l_{\text {lin }}=21 \mathrm{~mm}, g_{\text {lin }}=0.1 \mathrm{~mm}$, $w_{\text {lin }}=0.7 \mathrm{~mm}$; for multi-layer C-section: $l=15.7 \mathrm{~mm}, g=1 \mathrm{~mm}, s=0.1 \mathrm{~mm}$, $w=0.7 \mathrm{~mm}$. Linear: $\varepsilon_{r}=3.55, \tan \delta=0.0027$; multi-layer: $\varepsilon_{r l}=\varepsilon_{r 3}=3.55, \varepsilon_{r 2}=3.25$, $\tan \delta 1=\tan \delta 3=0.0027$ and $\tan \delta 2=0.005, h_{1}=h_{3}=0.8 \mathrm{~mm}, h=50 \mu \mathrm{m}, h_{\text {air }}=15 \mu \mathrm{m}$.

$h_{\text {air }}=15 \mu \mathrm{m}$ is considered for the rest of the article. We note in Fig. 4 (b), the return loss is worse than what is conventionally encountered with planar C-sections [30]. Nevertheless, it can be improved by increasing the thickness of the flexible dielectric $h$ or by adjusting the width of the center lines as shown in [4]. The structure shown Fig. 2 is comparable (not exactly the same because of a completely different fabrication process used) to the one presented in [4] with a constant width $w$. Similarly, the behavior in frequency around the resonance frequency of the structure is comparable to that observed in [4]. Note that the presence of the air gaps has little impact on the maximum of delay group. Despite the presence of these air layers, there is still a peak with a large value of up to $7 \mathrm{~ns}$ (see Fig. 4 (c)). However, the height of the gap is not used to change the coding of the tag and hence it won't take into account of the presence of air gap if this gap is constant form one tag to another. The coding is achieved by controlling the two geometrical parameters, width $w$ and length $l$. In the case of mass production, accurate folding can be done by the machines available in the paper industry.

The final obtained structure is shown in Fig. 2 and Fig. 3. Two different flexible substrates were used: Pyralux AP $\left(\varepsilon_{r}=3.25, \tan \delta=0.005\right.$, and $h=50 \mu \mathrm{m}$, which is the same thickness as in the case of LTCC in [4]) and PET

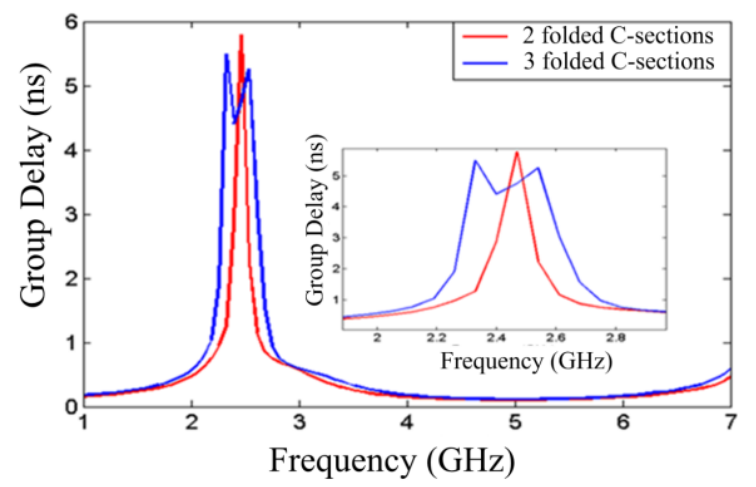

Fig. 7. Folded multilayer C-sections: over-coupling of the resonators results in the splitting of resonant peaks into two. Insight: zoomed view. 


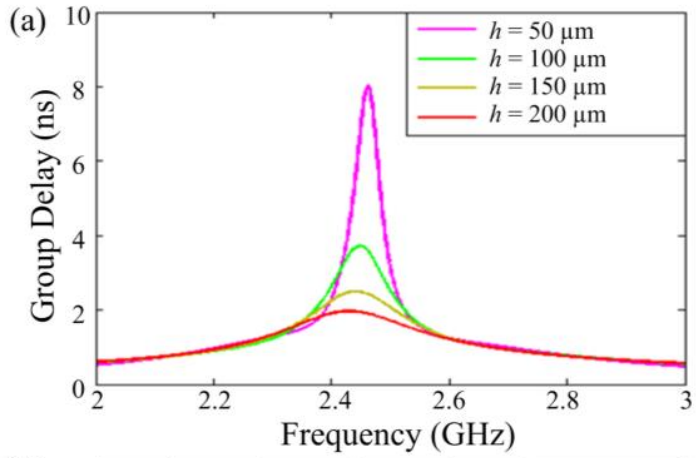

(b)

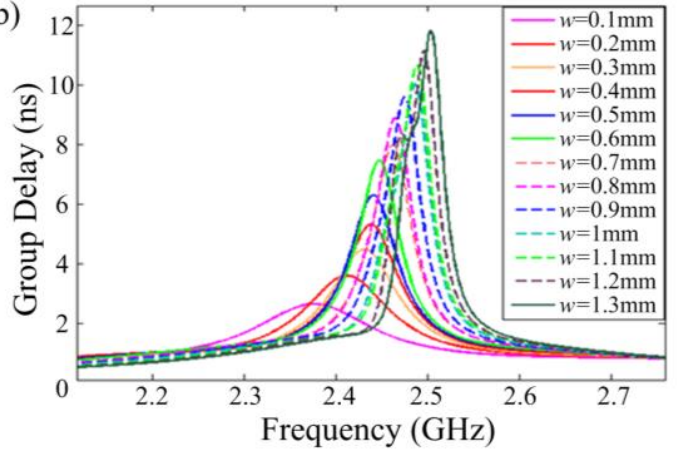

Fig. 8. GD peaks observed for different values of substrate height $h$ and line width $w$-the simulated structure is the one presented Fig. 2: (a) different substrate height, (b) different $w$ values; $l=15.7 \mathrm{~mm}, \varepsilon_{r l}=\varepsilon_{r 3}=3.55, \varepsilon_{r 2}=3.25$, $\tan \delta 1=\tan \delta 3=0.0027$, and $\tan \delta 2=0.005, h_{1}=h_{3}=0.8 \mathrm{~mm}, h=50 \mu \mathrm{m}$, $h_{\text {air }}=15 \mu \mathrm{m}, g=1 \mathrm{~mm}$.

(Polyethylene terephthalate) $\left(\varepsilon_{\mathrm{r}}=3.45\right.$, tan $\delta=0.005$, and $h=50 \mu \mathrm{m})$. These are the two cheap low loss substrates available in the market. Moreover, the folding has been tested using these substrates to verify that the metallic parts are not broken while folding the structure. The base substrate has a ground plane. However, the top substrate is without a ground plane. The top substrate is used to sandwich the flexible substrate making it affix tightly together. This design can be compared with the traditional microstrip design with a superstrate as represented in Fig. 3. Thus the model introduced in [27], [31] is used to calculate the effective permittivity $\varepsilon_{\text {reff }}$ of (1). In the proposed case, $h_{2}$ is the total height of the flexible substrate where the conductor is printed. In this configuration, $h_{2}=7 h$ as can be seen in Figs. 2 and 3.

The GD of the structure has been simulated for different configurations. It has been found that the GD increases tremendously with the folded multilayer structure. Moreover, the GD curve became narrowband in comparison to the linearly cascaded C-section.

The coupling coefficient of the multilayer structure is calculated as explained in Fig. 5 (a). Here, the structure used is stripline as shown in Fig. 5 (a). A full-wave simulation has been done and the coupling coefficient $k$ has been extracted from the S-matrix. Fig. 5 (b) shows the obtained coupling coefficient as a function of gap. In the multilayer case, the thickness of the flexible substrate $2 h$ determines the gap as shown in Fig. 5 (a). In practice, $100 \mu \mathrm{m}$ can be achieved. A comparison with $k$ obtained for linear $\mathrm{C}$-sections can also be seen Fig. 5 (b) (in this case, the gap is the space between the two microstrip lines placed on the same substrate). It is clear from the figure that multilayer design possesses a larger $k$ which implies a higher GD.
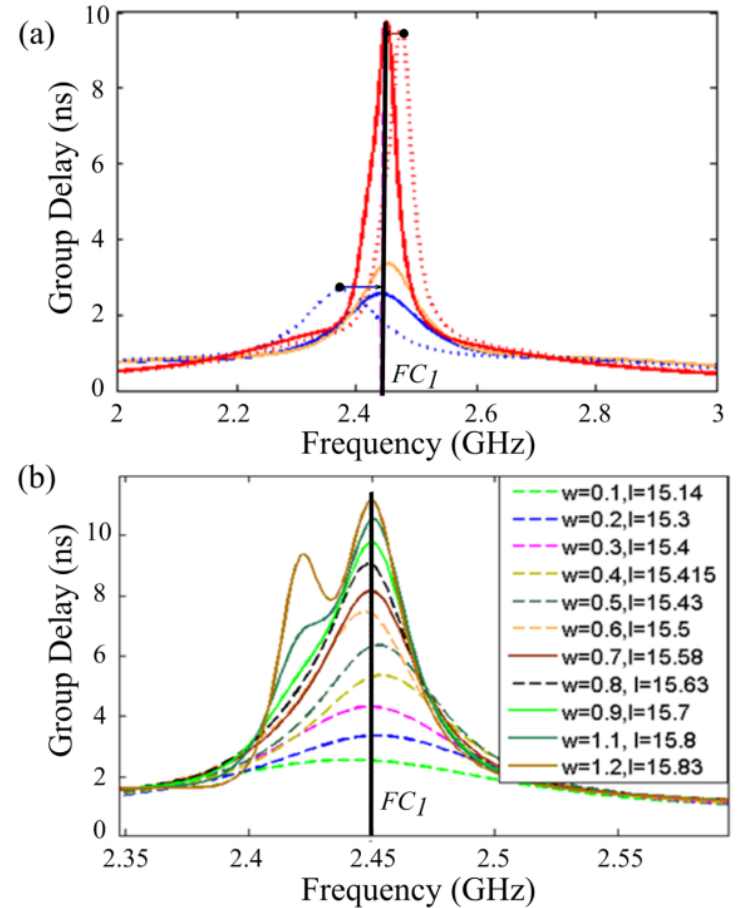

Fig. 9. Group delay curve produced by changing the width w and length $l$ of the folded multilayer $\mathrm{C}$-sections presented in Fig. 2. (a) The dotted curves represent GD produced for different width $w$ for a constant length $l$. Arrows represents the translation to a single frequency. The solid lines represent GD after translation to a single frequency by changing the length and width of the line. (b) Different $\mathrm{C}$-sections having a maximum GD at the same frequency $F c_{1}$. The maximum values of the GD are between 2 and $11 \mathrm{~ns}$. The different values used $(w, l)$ are indicated in the figure. All the units are in $\mathrm{mm} ; \varepsilon_{r l}=\varepsilon_{r 3}=3.55, \varepsilon_{r 2}=3.25, \tan \delta 1=\tan \delta 3=0.0027$, and $\tan \delta 2=0.005, h_{1}=h_{3}$ $=0.8 \mathrm{~mm}, h=50 \mu \mathrm{m}, h_{\text {air }}=15 \mu \mathrm{m}, g=1 \mathrm{~mm}$.

Fig. 6 shows the comparison of GD curves between two folded multilayered C-sections [Fig. 2 (a)] and 10 linearly cascaded C-sections (Fig. 5). Both produce a comparable delay. In the case of linear $\mathrm{C}$-sections, to produce the same amount of delay demands five times more number of $\mathrm{C}$ sections of multilayer design. The multilayer C-sections produces GD peaks with $22 \mathrm{MHz}$ of bandwidth. In contrast, those of linear $\mathrm{C}$-sections have $338 \mathrm{MHz}$. The reason for highly selective GD with significant magnitude is because of the coupling between each C-section. In the case of linear cascaded C-sections, as already explained, the coupling produced is the edge coupling. On the other hand, the coupling produced in the folded multilayer design is the broad side coupling. For the multilayer configuration, simulation has been done by increasing the number of $\mathrm{C}$-sections. It has been found that GD does not increase its value, instead the GD peak splits into two adjacent peaks as shown in Fig. 7. It occurs if the coupled resonators are over coupled [32], [33]. This occurs when the corresponding coupling coefficient is larger than a critical value amounting to $1 / Q_{0}$, where $Q_{0}$ is the quality factor of the resonant circuit.

It is why only the two folded C-sections (Fig. 1) has been used in the rest of the article. We also note that the splitting of the delay peak cannot be obtained with the classical planar Csection configuration.

Simulations have been done to prove its application in chipless RFID. To produce different tag combinations, the length of the C-sections $l$ has been varied. Indeed, we will see here that with only the use of two parametric variables, it is 

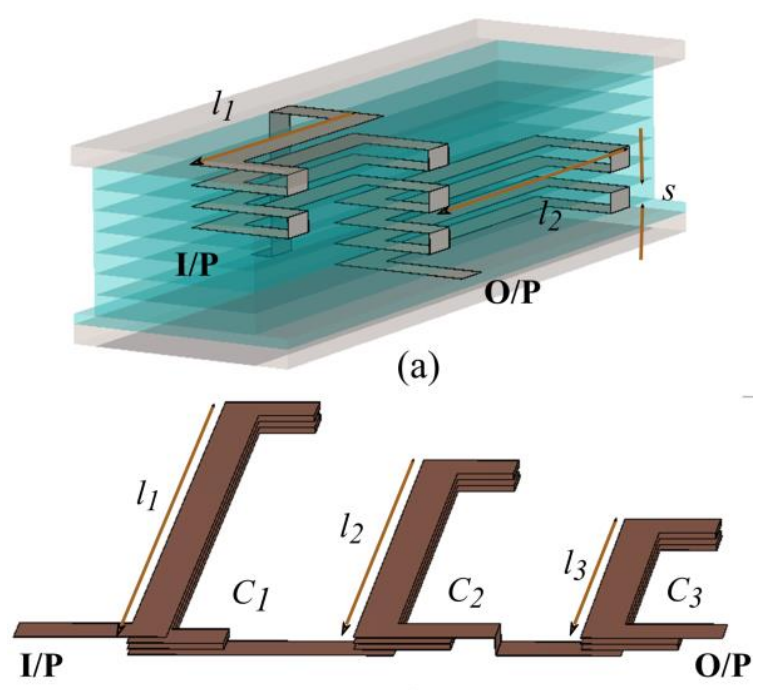

(b)

Fig. 10. (a) Folded multilayer design for two groups of $\mathrm{C}$-sections along with the design parameters. The structure has a dimension of $6.7 \cdot 24.5 \mathrm{~mm}^{2}$. (b) Folded multilayer design for $\mathrm{n}=3$ groups of $\mathrm{C}$-sections with $C_{l}$ as the first group, $C_{i}$ as the intermediate group, and $C_{n}$ as the nth group.

possible to control the maximum of the GD curve in frequency. It is an easy method to connect the geometry to a specific evolution of the GD (the maximum value of the GD at a given frequency) to encode information. As seen in (1), and also from simulations, the operating frequency shifts to the lower region, whereas the length $l$ increases. It is clear that $g$ plays an important role as in the case of length $l$. When $g$ increases, the GD peaks shift to the lower frequency region. This is because an increase in $g$ increases the total length of the $\mathrm{C}$-section.

Further, simulations for different flexible substrate height $h$ and width $w$ have also been conducted. Fig. 8 (a) and (b) shows the GD curves obtained for different $h$ and $w$, respectively. Likewise, Fig. 9 shows the GD curve produced by changing the width $w$ and length $l$ together to obtain a maximum at the same frequency. As shown in Fig. 8 (a), the GD decreases as the substrate height $h$ increases. This is because of the lower coupling between $\mathrm{C}$-sections. It is interesting to note that $w$ can easily adjust the value of GD as it can influence the coupling. $w$ can be more easily modified than $h$ to realize different configurations. The variation observed in frequency can be easily compensated by the length $l$. It has been found in the GD curve that a change in length only shifts the corresponding GD curve making the other constant thus rendering the two peaks independent of each other. This enables encoding at two different peaks. In comparison to planar configuration [24], here the frequency selectivity is high because of the coupling effect and hence allows the weak-delay delay zone to cascade more number of different C-section groups. Fig. 10 shows the GD curve obtained for two groups of folded multilayered C-section. As the delay peaks are highly narrowband, more frequency spans can be introduced in between two peaks as shown in the figure, which permits more delay levels at each frequency band. This in turn increases the capacity of coding. An example of independence of different delay peaks can be seen in Fig. 11 where each time the length of only one group has been changed even as the other remains constant. Similarly, $n$

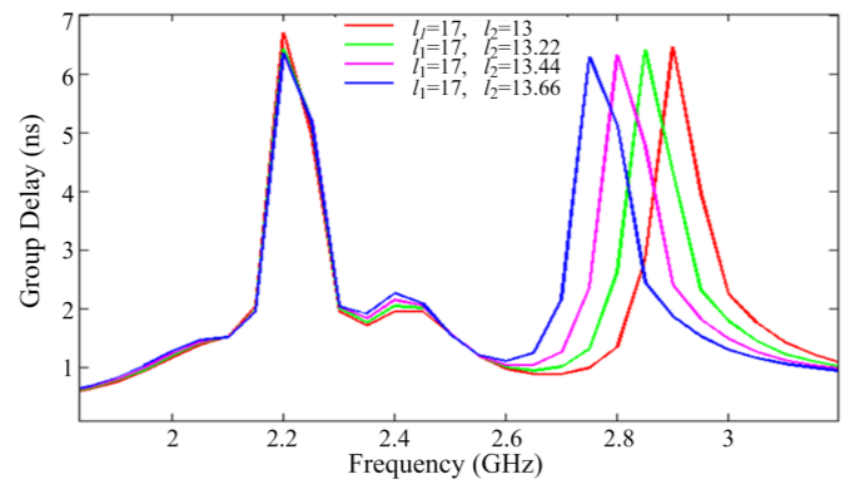

Fig. 11. Example of independence of different group delay peaks for the folded multi-layer tow group of C-sections given Fig. 10 (a). All the units are in $\mathrm{mm} . g=1 \mathrm{~mm}, w=0.7 \mathrm{~mm}, s=0.1 \mathrm{~mm}, \varepsilon_{r l}=\varepsilon_{r 3}=3.55, \varepsilon_{r 2}=3.25, \tan \delta 1=$ $\tan \delta 3=0.0027$ and $\tan \delta 2=0.005, h_{1}=h_{3}=0.8 \mathrm{~mm}, h=50 \mu \mathrm{m}, h_{\text {air }}=15 \mu \mathrm{m}$.

$\mathrm{C}$-sections can be folded as shown in Fig. 10 (b), provided, the periodic peak is considered when cascading the C-sections. Note that in Fig. 10 (b), the structure has been folded in a different manner with respect to Fig. 10 (a).

We will now see how the direct link between some geometric elements $(l$ and $w)$ and the shape of the transmitted signal by the $\mathrm{C}$-section enables encoding an identifier to realize a chipless tag.

\section{Calculation Of Coding CaPacity}

Two kinds of approaches are explained here. Either ISM bands can be used for high power and high reading range applications or UWB regulation [34] used, which permits a reading range less than $1.5 \mathrm{~m}$ and can be used for short range applications. As UWB permits more frequency bands, the coding capacity will be higher than that of ISM bands. First, the operating frequency is chosen as $2.45 \mathrm{GHz}$. This is an unlicensed ISM band where the allowed frequency range is from $2.4 \mathrm{GHz}$ to $2.5 \mathrm{GHz}$ with $100 \mathrm{MHz}$ of bandwidth. The length of the C-section has been calculated accordingly and simulations haven been conducted for different lengths $l$ and widths $w$. As already shown in Fig. 8, increasing the width causes GD curves shifting to the upper frequency. If the width $w$ is increased by varying the length $l$, at a single frequency, we have several delay levels as shown in Fig. 9. As already

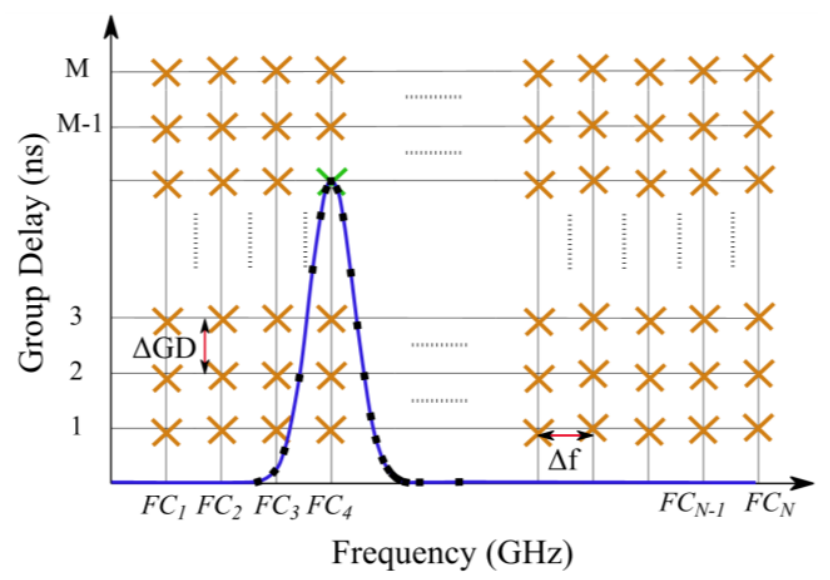

Fig. 12. Time-Frequency constellation diagram that explains the calculation of coding capacity in the case of folded multilayered single group of $\mathrm{C}$ sections. Each circle represents the maximum of a GD curves obtained with the multilayer C-section. 
explained, the GD value is more in this case and also the delay peaks are highly narrowband, which makes it suitable for cascading different groups of $\mathrm{C}$-sections and to increase the coding capacity. Thus, from Fig. 9, it is clear that a change in width creates different delay levels and change in length arranges all the GD curves at a single frequency. From the figure, we can easily infer that the change in length corresponds to each width: at a single frequency $F C_{1}=2.45 \mathrm{GHz}, 11$ different delay levels with a minimum delay of $0.8 \mathrm{~ns}$ can be considered. From Fig. 9, it is clear that the minimum delay is approximately $2 \mathrm{~ns}$ and maximum delay is $10.8 \mathrm{~ns}$ which in turn gives 11 different levels with a $0.8 \mathrm{~ns}$ delay difference. If we consider a frequency resolution of $25 \mathrm{MHz}(22 \mathrm{MHz}$ is the minimum possible frequency resolution as shown in Fig. 6), we can have five different operating frequencies $F C_{1}, F C_{2}, F C_{3}, F C_{4}$, and $F C_{5}$ within the allowed ISM bandwidth between 2.4 and $2.5 \mathrm{GHz}$. This leads to a number of configurations equal to $11 \cdot 5$. Fig. 12 explains the constellation diagram used to calculate the coding capacity. Consider $M$ as the maximum possible delay variations and $N$ as the number of possible frequency bands. The coding capacity $C$ can be written as $C=\log _{2}(M \cdot N)$. In the proposed case, $C=\log _{2}(11 \cdot 5)=5.78$ bits. In the ISM band at $5.8 \mathrm{GHz}$, the maximum allowed bandwidth is $150 \mathrm{MHz}$, which in turn produces a coding capacity of 6.27 bits $\left(C=\log _{2}(11 \cdot 11)=6.27\right.$ bits $)$.

Similar to what has been introduced in [24] concerning planar C-section, structures composed of cascaded noncommensurate $\mathrm{C}$-section groups are also consistent with the folding approach described here. Indeed, by using several C-

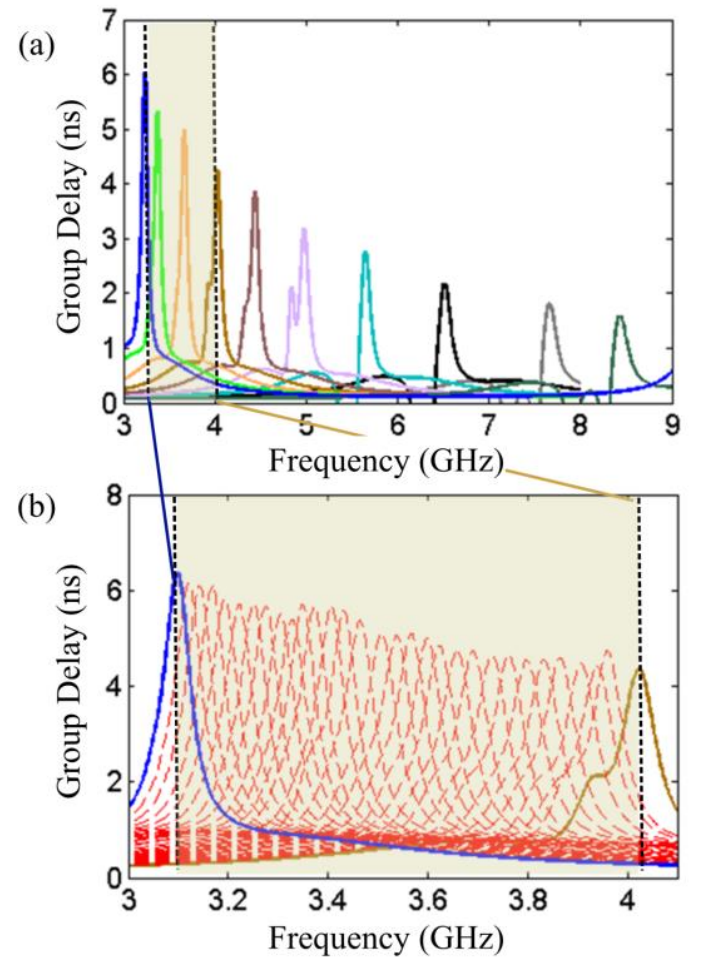

Fig. 13. Different GD response obtained by changing the length $l$ of one group of C-sections (range 9-12 mm), (a) in the band 3.1-9 GHz, (b) in the band 3-4 GHz with $22 \mathrm{MHz}$ of frequency resolution; $g=1 \mathrm{~mm}, w=0.7 \mathrm{~mm}$, $s=0.1 \mathrm{~mm}, \varepsilon_{r 1}=\varepsilon_{r 3}=3.55, \varepsilon_{r 2}=3.25, \tan \delta 1=\tan \delta 3=0.0027$ and $\tan \delta 2=0.005$, $h_{1}=h_{3}=0.8 \mathrm{~mm}, h=50 \mu \mathrm{m}$, and $h_{\text {air }}=15 \mu \mathrm{m}$. section groups, the coding capacity can be significantly improved. If a structure with two C-sections of different lengths [see Fig. 9 (a)] is considered, two independent GD peaks can be used to encode the information. It is thus possible to increase substantially the amount of information that can be encoded. For instance, if we consider two groups of C-sections, then the coding capacity will be $C=$ $\log _{2}\left(\left(M_{1} \cdot N_{1}\right) \cdot\left(M_{2} \cdot N_{2}\right)\right)$, where $M_{1}$ and $M_{2}$ are the maximum possible delay variations for the first and second group, and $N_{l}$ and $N_{2}$, respectively, are the possible frequency bands for the two groups. Thus, a multilayer $\mathrm{C}$-section group that can operate in ISM bands at $2.45 \mathrm{GHz}$ and $5.8 \mathrm{GHz}$ can produce a capacity of coding of 12.05 bits $(5.78+6.27)$. This value is significant for time domain tags [except for Surface Acoustic Wave (SAW) tag] where the already reported highest capacity of coding is 8 bits for a tag dimension of 9.5 . $4.5 \mathrm{~cm}^{2}$ (without the antennas) [34], that is, 32 times larger than the surface of the multilayer tag introduced here.

As seen in Fig. 10, with the proposed fabrication process, more number of $\mathrm{C}$-section groups can be realized and used such as in [25]. In general, the coding capacity for $n \mathrm{C}$-section groups will be (this is the maximum possible configurations) $\log _{2}\left(\prod_{\mathrm{i}=1}^{\mathrm{n}} M_{i} \cdot N_{i}\right)$. In the case of UWB band, frequency band from 3.1 to $9 \mathrm{GHz}$ is considered. As the periodic peak of the GD of $3.1 \mathrm{GHz}$ occurs at $9.3 \mathrm{GHz}$, the frequency band is limited at $9 \mathrm{GHz}$. Fig. 13 (a) shows the GD peak obtained by changing the length of the C-section of one group. As there are $n$ number of peaks, there are $n$ number of tag combinations. Fig. 13 (b) shows the number of peaks produced with a $22 \mathrm{MHz}$ resolution in the frequency band 3$4 \mathrm{GHz}$. Changing the width permits to code different delay levels as explained in the case of ISM bands.

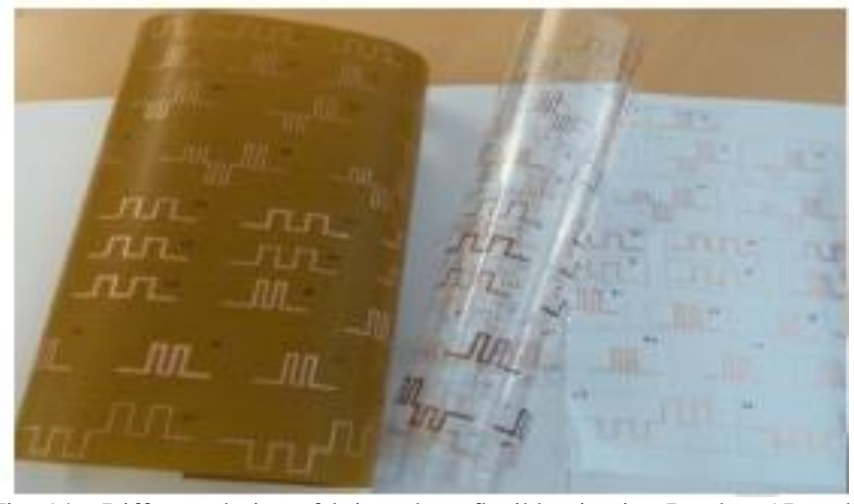

Fig. 14. Different designs fabricated on flexible circuits: Pyralux AP and PET.

For this design, operating bandwidth of almost $6 \mathrm{GHz}$ between 3.1-9 GHz is feasible. Within this band, six GD peaks (that is, a structure composed of six C-section groups) can be distributed. Thus, each peak has a frequency span of 1 $\mathrm{GHz}$ in which it can be shifted [35]. $1 \mathrm{GHz}$ is chosen to make these six different peaks completely independent. In such a configuration, an extrapolation of the coding capacity can be done such as in [35]. By this method, a coding capacity of 43.3 bits is possible with six C-section groups with a frequency resolution of $22 \mathrm{MHz}$. This can be compared with the code 39 barcode [36], where 43 bits are used for the identification or EAN 13 barcode, where 41 bits can be coded. 



Fig. 15. Different steps used to develop the prototype on the flexible substrates. (a) Each design separately. Flexible substrates are shown before or after folding. (b) Folded designs, in this case, are glued, (c) the base substrate with ground plane and connectors along with the top substrate without ground plane. (d) Folded design affixed to the base substrate.

\section{Two PorT's Folded C-SECTION MEASUREMENT}

The designs explained above were fabricated on Pyralux AP [37] using the traditional photolithographic process and on PET using the low cost digital print and plate technology [38]. Fig. 14 shows the fabricated designs on Pyralux AP and PET, both having a thickness of $50 \mu \mathrm{m}$. The flexibility of the substrate can be seen in this figure. It can be easily used for folding. The devices fabricated on PET exhibits a copper thickness of $17 \mu \mathrm{m}$. Therefore, care should be taken to fold the substrate, otherwise there is a chance of losing the electrical connection. Rogers R4003 ( $\left.\varepsilon_{r}=3.55, \tan \delta=0.0027, h=0.8 \mathrm{~mm}\right)$ is used as the base and top substrate. The designs on flexible substrate were cut, folded, and affixed to the base substrate. Fig. 15 shows the process used. As shown in Fig. 15 (d), glue can be used to affix the folded flexible substrate. Fig. 16 (a) shows the measured GD of a folded multilayer C-section fabricated on PET. As presented in Fig. 15 (d), the measurement was done by connecting the prototype in between the two ports of a Network Analyzer (PNA N5222A). The maximum GD value obtained is nearly $2.25 \mathrm{~ns}$. To prove the influence of the glue, a simulation has been done by increasing the thickness $h$ between the layers. It was found that a thickness of $150 \mu \mathrm{m}$ instead of $50 \mu \mathrm{m}$ can produce a $2 \mathrm{~ns}$ delay as shown in Fig. 16 (b). The frequency shift of $80 \mathrm{MHz}$ is because of the permittivity of the glue.

Thus the glue was omitted in further measurements. The folded device was tightly covered with the base and top substrates using duct tape. This was to keep the structure very close to the simulated configuration. By this method, it is possible to reduce the presence of air layers that increase the space between the coupled lines that then decreases the coupling. By controlling the thickness of the entire multilayer device, we can reduce the air gap and improve the coupling between the C-sections. Fig. 17 shows the measured Sparameters and GD of a multilayer $\mathrm{C}$-section fabricated on Pyralux AP. As previously discussed, simulation was done by adding a layer of air with a thickness of $15 \mu \mathrm{m}$ in between each flexible substrate layers. The comparison of the GD between measurements and simulations with air layers is shown Fig. 17 (c). By considering this specific air layer thickness, it was found that the frequency agrees well with that of measurement. Therefore, even with the use of duct tape, it is clear that an air gap still remained in the structure. We observe that the structure is very sensitive to the exerted pressure. It quickly reaches the limits of what can be done manually. To organize more robust devices or with a higher
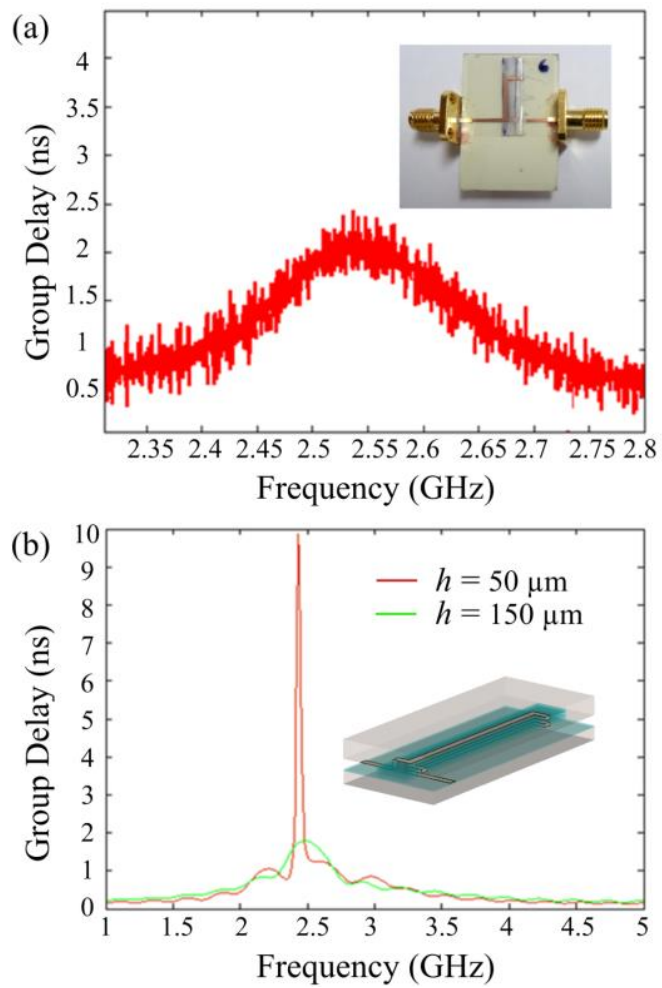

Fig. 16. Different GD curves obtained by measurement and simulation for one group of folded multilayer C-sections realized on PET. (a) Measured GD for the device explained in Fig. 1 with $l=15.7 \mathrm{~mm}, g=3 \mathrm{~mm}, w=0.7 \mathrm{~mm}$, and $s=0.1 \mathrm{~mm}$. (b) Simulated result for two different thickness $h$ of substrate, $50 \mu \mathrm{m}$ and $150 \mu \mathrm{m}$, which explains the influence of additional equivalent thickness produced by the glue; $\varepsilon_{r l}=\varepsilon_{r 3}=3.55, \varepsilon_{r 2}=3.45, \tan \delta 1=\tan \delta 3=0.0027$, and $\tan \delta 2=0.005, h_{1}=h_{3}=0.8 \mathrm{~mm}, h_{\text {air }}=15 \mu \mathrm{m}$. 

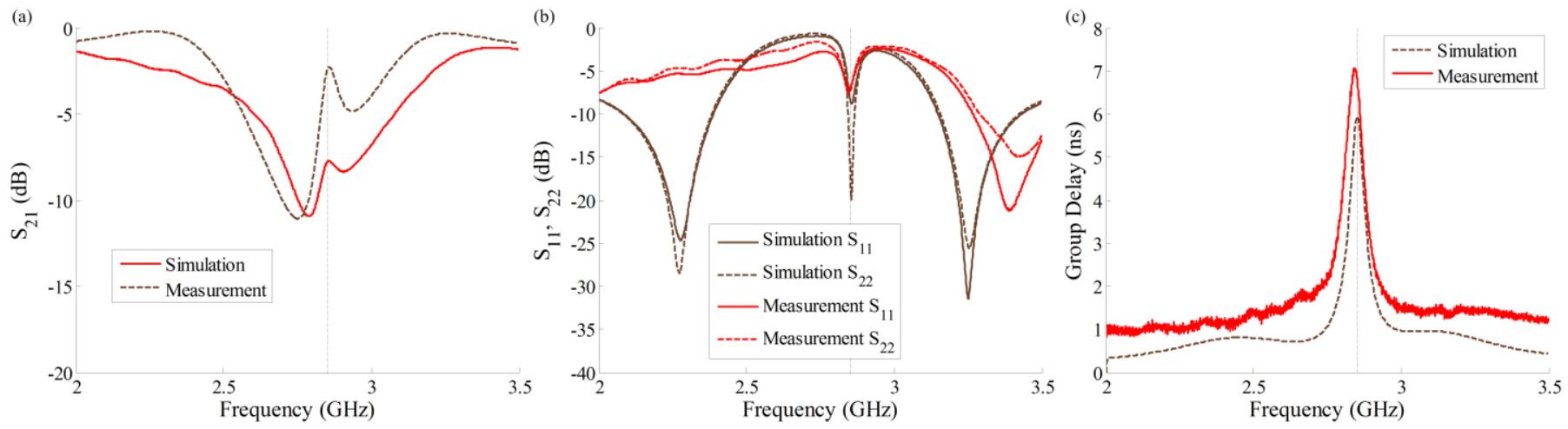

Fig. 17. Comparison between measured and simulated S-parameters and GD for one group of folded multilayer C-sections realized on Pyralux AP (same sample as the one presented in Fig. 18). (a) $\mathrm{S}_{21}$, (b) $\mathrm{S}_{11}, \mathrm{~S}_{21}$, and (c) GD; $l=11.4 \mathrm{~mm}, \varepsilon_{r l}=\varepsilon_{r 3}=3.55, \varepsilon_{r 2}=3.25, \tan \delta 1=\tan \delta 3=0.0027$, and $\tan \delta 2=0.005, h_{1}=h_{3}=0.8 \mathrm{~mm}$, $h=50 \mu \mathrm{m}, g=3 \mathrm{~mm}, w=0.7 \mathrm{~mm}, h_{\text {air }}=15 \mu \mathrm{m}$.

number of $\mathrm{C}$-sections, it is important to use a structure that precedes the encapsulating structure in a rigid package. By exerting some pressure during molding, it could be possible to reduce or even remove air gaps within the coupled line and thus to obtain the desired thickness. The S-parameters of the realized folded multilayer structure are compared with fullwave results in Fig. 17 (a) and (b). Good agreement is found, which validates the introduced fabrication process. Nevertheless, the discrepancies observed are attributed to inaccuracies of the sample realization, where the different folds are handmade. But we can observe in Fig. 17 the same general evolution in frequency of the S-parameters and GD.

Measurement was further repeated using the plastic plier with the multilayer $\mathrm{C}$-section fabricated on Pyralux AP. Plastic films are sufficiently rigid so that the structure remains flat. By applying pressure on the folded C-section, although in practice one obtains a structure to the ideal case of the picture represented in Fig. 2 (b). In Fig. 18, we can see that a strong variation is observed when different configurations are tested. Note that in this case, the top substrate has been removed during the measurement to apply a very strong stress. The presence of the plastic plier affects the measurement results, and it was found that the GD seems to be decreasing when the position of the plier is changing to configurations where the stress is less homogenously distributed on the sample. This is because of the low coupling and also because of the presence of air between each flexible substrate layer. Anyway, it is clear that in such a configuration, without the top substrate, the GD variation is quite significant and could be used to realize a pressure sensor. Note that very important GD value can be obtained ( $30 \mathrm{~ns}$ ) by this method. This value would be very difficult to obtain with a classical planar configuration, where $10 \mathrm{C}$-sections are needed to reach $7 \mathrm{~ns}$ of GD. It is also interesting to see that a notch filter configuration, similar to the one observed in Fig. 4 without air gap, can be obtained in practice.

\section{Chipless Tag Measurement}

To prove the concept of the chipless device based on folded $\mathrm{C}$-session, a chipless tag composed of a folded C-session implemented at the center of a transmission line ended by two antennas in orthogonal orientation is investigated. Note that this approach is similar to what has already done in [25]. The same antenna structure in [25] has been used here to realize a (a)
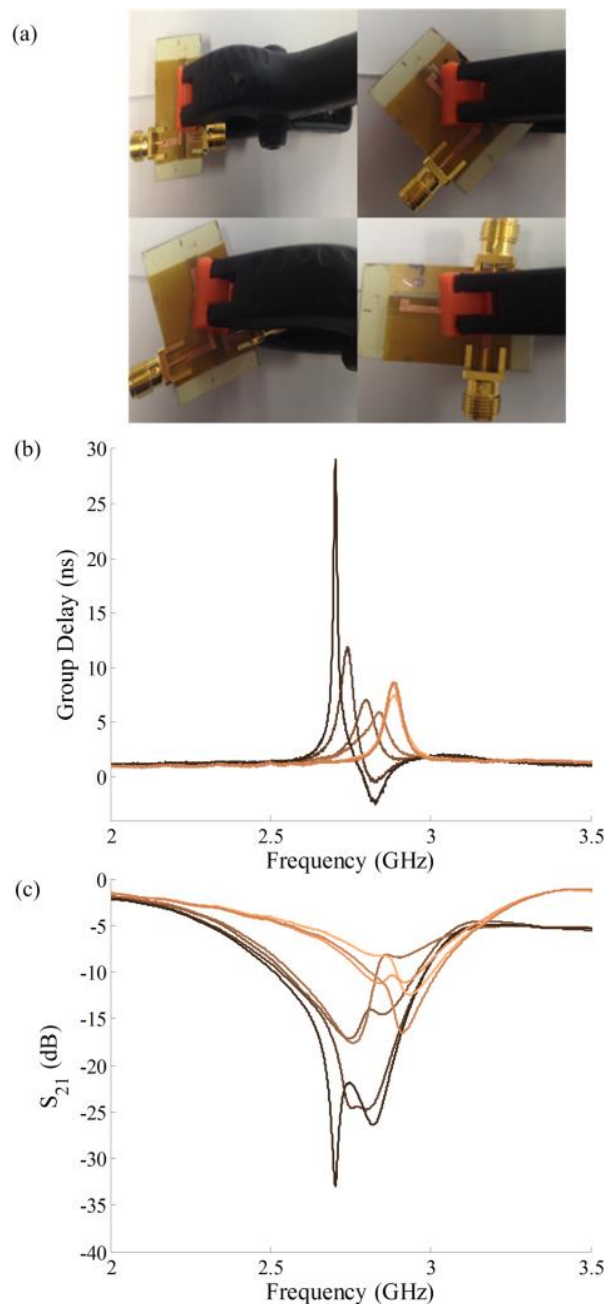

Fig. 18. Different plier positions along with the corresponding measured group delays. (a) Plier positions. Corresponding group delays (b) and $\mathrm{S}_{21}$ (c).

wireless interrogation of the folded $\mathrm{C}$-section chipless tag. Photographs of the device (the transmission line ended by two antennas realized on Rogers R4003) with the folded C-session, and the same structure where a top substrate has been added (see Fig. 2) are presented, respectively, in Fig. 19 (a) and 19 (b). With such realization process, we observe that the Csection is similar to the one characterized in Fig. 17; Rogers R4003 is used as the base and top substrate, and Pyralux AP is used for the folded part. The only difference could be the air gap of the folded structure. With such realization, the 
thickness is directly linked to the pressure applied or the manner used to fix together the bottom and the top substrates. The measurement setup previously introduced in [39, Fig. 6] is used. To simulate a real environment, the room used for the measurement contains tables, chairs, and many metal elements. The antenna used is a SATIMO QH2000 dual polarization that operates in the $2-32 \mathrm{GHz}$ band. Its gain is between $6-11 \mathrm{dBi}$ from $2-10 \mathrm{GHz}$. Thanks to this antenna, a mono-static radar configuration can be used. Port 1 of the vector network analyzer (VNA) is connected to the vertical polarization antenna port for excitation, while port 2 is connected to the horizontal polarization antenna port for receiving. The S-parameter at the VNA provides the tag response in cross-polarization $\left(S_{21}\right)$ which is used to extract the tag information. The chipless tag and the reader antenna were mounted on plastic stands and the tag was placed distance of $40 \mathrm{~cm}$.

In the same manner as for [25], only one measurement is needed to perform the identification of the tag. This means that the measurement of a reference tag or the empty environment is not used and hence avoids all the calibration techniques which make the whole system complex. The post processing applied to the signal (the $S_{21}$ measured with the VNA as previously explained) is the same as the one introduced in [25]. Indeed, in order to separate the structural mode and different tag modes at the frequency of interest, Continuous Wavelet Transform (CWT) is used. The CWT performs a correlation analysis and as a consequence maximum output can be expected when the input signal mostly resembles the wavelet template. This input signal will be the time domain signature of the tag with amplitude in Volt. Consider the backscattered response of the tag after time windowing as $\mathrm{S}_{21}(t)$. A Gaussian signal modulated at a carrier frequency of $F C$ is chosen as the known deterministic signal $p(t)$.

Thus, $p(t)=e^{\left(\frac{-t^{2}}{2 t v}\right)} \cdot \cos (2 \pi \cdot F C \cdot t)$

where $t_{v}$ is the time domain parameter which consider the bandwidth of the signal $(\mathrm{BW}=0.1)$. Thus the wavelet template signal $p(t)$ is a signal which can be parameterized in frequency and bandwidth. A cross correlations of this signal with $\mathrm{S}_{21}(t)$ has been done. Finally the maximum of this cross-correlation gives the unknown location parameter $\tau$ :

$\tau=\max \left(\mathrm{S}_{21}(t) * p(t)\right)$, where $*$ represents the crosscorrelation operation.

In our case, $\tau$ is a combination of two peaks, the first peak represents the structural mode and the second peak represents the tag mode. The difference $\Delta t$ between these two peaks gives the delay of the tag, it means the tag ID.

Fig. 20 shows the maximum output of the correlation, which in turn corresponds to the group delay produced by the tag (the folded C-section and the two cross-polarized antennas). We clearly observe the presence of the two peaks, and a maximum time deviation $\Delta \mathrm{t}$ of $7.46 \mathrm{~ns}$ is obtained at frequency $2.88 \mathrm{GHz}$. It has been proved in [25] that this time deviation is the sum of the delay introduced by the C-section and the one form the two antennas plus the transmission line. The contribution of the antennas and the line is estimated by simulation to be $1 \mathrm{~ns}$. So the contribution of the folded Csection is $6.46 \mathrm{~ns}$. This value is close to the one obtained in
Fig. 17 (c). Indeed in this figure, the maximum GD is $7 \mathrm{~ns}$ at a frequency of $2.85 \mathrm{GHz}$. A difference of $0.5 \mathrm{~ns}$ is observed; this difference is less than the minimum delay of $0.8 \mathrm{~ns}$ what we have considered. This experimentation shows that the delay between structural mode and tag mode $\Delta \mathrm{t}$ can be used for the encoding. We also prove the concept of chipless tag based on folded C-sections.

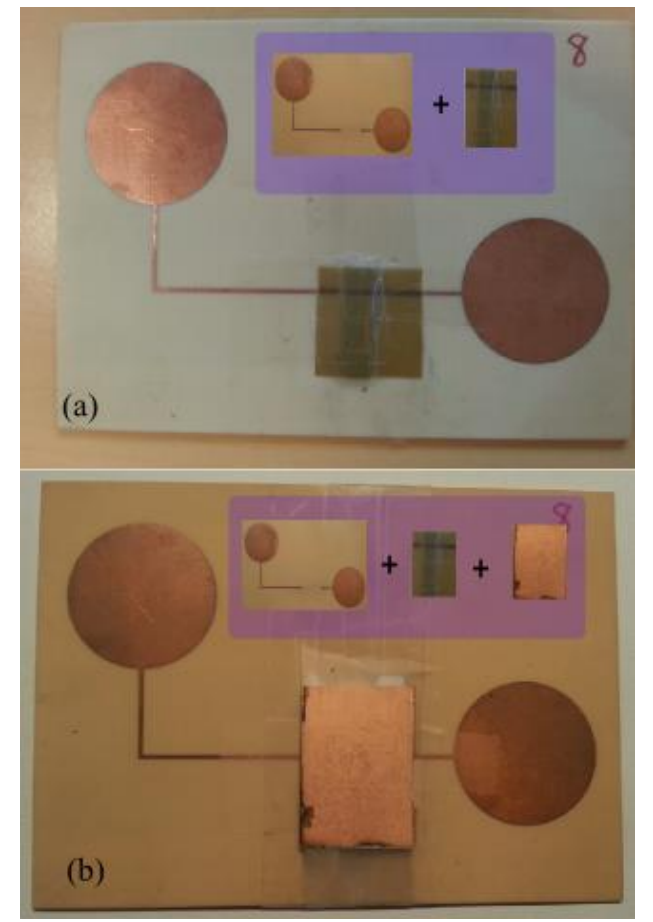

Fig. 19. Photographs of the tag under test. The tag is shown without the top subtract (a); and with (b).

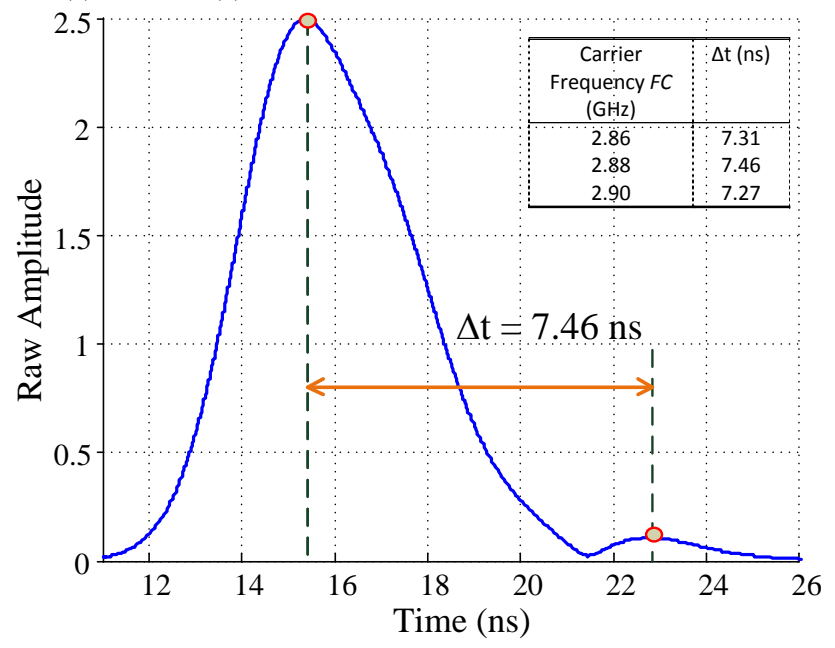

Fig. 20. Measured delays of folded chipless tag [see Fig. 19 (b)] obtained using wavelet approach at frequency $2.88 \mathrm{GHz}$. This measurement was done without a reference tag at a distance of $40 \mathrm{~cm}$.

\section{CONCLUSION}

A folded multilayer structure realized by an original process is introduced in this article. With this approach, it is possible to obtain high performing multilayer structures very easily by using common material and without any facilities such as clean room or even expensive equipment. Structures with worse performances but almost comparable specifications than the one realized with LTCC fabrication process can be 
obtained by this method. The proposed structure can be considered as an evolution of the classical C-sections already in use to realize chipless tags. More precisely, this is an innovative concept, made possible by a fusion between an original fabrication process and the $\mathrm{C}$-sections, which are known to have a high potential not only for the development a new generation of chipless tag but also chipless sensor tags. It is also interesting to note that this structure can be designed to be used as a filter. In the studied configuration, the proposed device offers a significant amount of GD and highly narrow band delay peaks. These two features enable a high capacity of coding for time domain tags. A coding capacity of 5.07 bits using a single group of folded C-sections and 12.05 bits using multigroup of C-sections, in the allowed unlicensed ISM band, is proposed using the obtained simulation results. It is also expected to provide 43.27 bits with UWB regulations. It is highly significant for time domain tags, as such performances have never been obtained before.

The solution for accurately folding the structure is to use a specific machine available in the paper industry. These machines allow folding in a regular manner with high speed by setting the pressure on the folded portions. However it is incompatible with the production of small series items such as the prototypes we are characterizing and thus brings the significance of folding the structures in hand. The multilayer structure can be created by manual folding at each particular point so as to make one C-section on the top of another separated by a dielectric in between. The obtained results prove that this low cost technique can be successfully used, contrary to the classical LTCC technique using via. Even if some technical improvements have to be implemented to reach high performing structures, it has been found that such low cost devices, realized by hands, can offer a significant amount of GD. By pressing the structure, it is clear that the coupling between $\mathrm{C}$-sections is increased by reducing the presence of air. The structure allows fabrications on cheap and green substrates. It is clear that the air gap plays a significant role in the realization. It is therefore necessary to find a consistent way for achieving this requested precision. It is clear that if this accuracy cannot be reached, the amount of information contained in the tags would be revised downward. However, it does not call into question the principle of the tags shown here.

\section{REFERENCES}

[1] L. Pergola, R. Gindera, D. Jager, and R. Vahldieck, "An LTCC-Based Wireless Transceiver for Radio-Over-Fiber Applications," IEEE Trans. Microw. Theory Techn., vol. 55, no. 3, pp. 579-587, 2007.

[2] L. Jong-Hoon, N. Kidera, S. Pinel, J. Laskar, and M. M. Tentzeris, "Fully Integrated Passive Front-End Solutions for a V-band LTCC Wireless System," IEEE Antennas Wireless Propag. Lett., vol. 6, pp. 285-288, 2007.

[3] K.-S. Chin, J.-L. Hung, C.-W. Huang, J. S. Fu, and N. C. Karmakar, "Compact LTCC bandpass filter with vertically folded structure," Microw. Opt. Technol. Lett., vol. 53, no. 6, pp. 1389-1394, 2011.

[4] Y. Horii, S. Gupta, B. Nikfal, and C. Caloz, "Multilayer BroadsideCoupled Dispersive Delay Structures for Analog Signal Processing," IEEE Microw. Compon. Lett., vol. 22, no. 1, pp. 1-3, 2012.

[5] N. L. VandenBerg and L. P. B. Katehi, "Broadband vertical interconnects using slot-coupled shielded microstrip lines," IEEE Trans. Microw. Theory Techn., vol. 40, no. 1, pp. 81-88, 1992.
[6] L. Zhu and W. Ke, "Ultrabroad-band vertical transition for multilayer integrated circuits," IEEE Microw. Guided Wave Lett., vol. 9, no. 11, pp. 453-455, 1999.

[7] G. Qizheng, Y. E. Yang, and M. A. Tassoudji, "Modeling and analysis of vias in multilayered integrated circuits," IEEE Trans. Microw. Theory Techn., vol. 41, no.2, pp. 206-214, 1993.

[8] R. Valois, D. Baillargeat, S. Verdeyme, M. Lahti, and T. Jaakola, "High performances of shielded LTCC vertical transitions from DC up to 50 GHz," IEEE Trans. Microw. Theory Techn., vol. 53, no. 6, pp. 20262032, 2005.

[9] F. P. Casares-Miranda, C. Viereck, C. Camacho-Penalosa, and C. Caloz, "Vertical microstrip transition for multilayer microwave circuits with decoupled passive and active layers," IEEE Microw. Compon. Lett., vol. 16, no. 7, pp. 401-403, 2006.

[10] E. Perret, Radio Frequency Identification and Sensors: From RFID to Chipless RFID. London, UK: Wiley-ISTE, 2014.

[11] K. Fuchi, J. Tang, B. Crowgey, A. R. Diaz, E. J. Rothwell, and R. O. Ouedraogo, "Origami Tunable Frequency Selective Surfaces," IEEE Antennas Wireless Propag. Lett., vol. 11, pp. 473-475, 2012.

[12] M. Reeb, "Method for the continuous flow make of customized planar electrical circuits," U.S. Patent 4935093 A, June 19, 1990.

[13] A. Vena, E. Perret, and S. Tedjini, "A Fully Printable Chipless RFID Tag With Detuning Correction Technique," IEEE Microw. Compon. Lett., vol. 22, no.4, pp. 209-211, March 2012.

[14] S. Tedjini, N. Karmakar, E. Perret, A. Vena, R. Koswatta, and R. EAzim, "Hold the Chips: Chipless Technology, an Alternative Technique for RFID," IEEE Microw. Mag., vol. 14, pp. 56-65, July 2013.

[15] S. Preradovic, I. Balbin, N. Karmakar, and G. Swiegers, "Chipless frequency signature based RFID transponders," in European Conf. Wireless Technology, Amsterdam, 2008, pp. 302-305.

[16] A. Vena, E. Perret, and S. Tedjini, "Chipless RFID tag using hybrid coding technique," IEEE Trans. Microw. Theory Techn., vol. 59, no. 12, pp. 3356-3364, 2011.

[17] S. Botao, C. Qiang, Y. Amin, D. S. Mendoza, L. Ran, and Z. Li-Rong, "An ultra-low-cost RFID tag with 1.67 Gbps data rate by ink-jet printing on paper substrate," in IEEE Asian Solid State Circuits Conf. 2010, pp. $1-4$.

[18] I. Jalaly and I. Robertson, "RF barcodes using multiple frequency bands," presented at the IEEE MTT-S Int. Microw. Symp. Digest, June12-17, 2005.

[19] S. Preradovic, I. Balbin, N. C. Karmakar, and G. F. Swiegers, "Multiresonator-based chipless RFID system for low-cost item tracking," IEEE Trans. Microw. Theory Techn., vol. 57, no. 5, pp. 1411$1419,2009$.

[20] A. Vena, E. Perret, and S. Tedjini, "Design of Compact and Auto Compensated Single Layer Chipless RFID Tag," IEEE Trans. Microw. Theory Techn., vol. 60, no. 9, pp. 2913-2924, Sep. 2012.

[21] M. A. Islam and N. C. Karmakar, "A Novel Compact Printable DualPolarized Chipless RFID System," IEEE Trans. Microw. Theory Techn., vol. 60, no.7, pp. 2142-2151, 2012.

[22] A. Vena, E. Perret, and S. Tedjini, "High Capacity Chipless RFID Tag Insensitive to the Polarization," IEEE Trans. Antennas Propag., vol. 60, no. 10, pp. 4509-4515, Oct. 2012.

[23] C. M. Nijas, U. Deepak, P. V. Vinesh, R. Sujith, S. Mridula, K. Vasudevan, and P. Mohanan, "Low-Cost Multiple-Bit Encoded Chipless RFID Tag Using Stepped Impedance Resonator," IEEE Trans. Antennas Propag., vol. 62, no. 9, pp. 4762-4770, 2014.

[24] R. S. Nair, E. Perret, and S. Tedjini, "A Temporal Multi-Frequency Encoding Technique for Chipless RFID Based on C-Sections," Progress Electromagn. Res. B, vol. 49, pp. 107-127, 2013.

[25] R. S. Nair, E. Perret, and S. Tedjini, "Group delay modulation for pulse position coding based on periodically coupled C-sections," Ann. telecommun., vol. 68, pp. 447-457, 2013.

[26] R. Nair, E. Perret, and S. Tedjini, "Temporal Multi-Frequency Encoding Technique for Chipless RFID Applications," presented at the IEEE MTT-S Int. Microw. Symp. Digest, Montréal, Canada, 2012.

[27] Z. Shun-Shi, L. Gang, and G. Qasim, "Closed form expressions for resonant frequency of rectangular patch antennas with multidielectric layers," IEEE Trans. Antennas Propag., vol. 42, no. 9, pp. 1360-1363, 1994.

[28] R. K. Settaluri, A. Weisshaar, C. Lim, and V. K. Tripathi, "Design of compact multilevel folded-line RF couplers," IEEE Trans. Microw. Theory Techn., vol. 47, no. 12, pp. 2331-2339, 1999.

[29] A. Vena, E. Perret, S. Tedjini, G. Eymin-Petot-Tourtollet, A. Delattre, F. Garet, and Y. Boutant, "Design of chipless RFID tags printed on paper 
by flexography," IEEE Trans. Antennas Propag., vol. 61, no. 12, pp. 5868-5877, 2013.

[30] S. Gupta, A. Parsa, E. Perret, R. V. Snyder, R. J. Wenzel, and C. Caloz, "Group-Delay Engineered Noncommensurate Transmission Line AllPass Network for Analog Signal Processing," IEEE Trans. Microw. Theory Techn., vol. 58, no. 9, pp. 2392-2407, 2010.

[31] P. Bhartia, I. Bahl, R. Garg, and A. Ittipiboon, Microstrip antenna design handbook. Boston, MA: Artech House, 2001.

[32] H. Jia-Sheng and M. J. Lancaster, "Cross-coupled microstrip hairpinresonator filters," IEEE Trans. Microw. Theory Techn., vol. 46, no. 1, pp. 118-122, 1998.

[33] B. I. Bleaney and B. Bleaney, Electricity and magnetism. London: Oxford University Press, 1976.

[34] ETSI. (2008). TS 102754 V1.2.1, "Electromagnetic compatibility and Radio spectrum Matters (ERM); Short Range Devices (SRD);Technical characteristics of Detect-And-Avoid (DAA) mitigation techniques for SRD equipment using Ultra Wideband(UWB) technology", (2015) [Online]. Available: http://www.etsi.org/deliver/etsi_ts/102700_102799/102754/01.02.01_60 /ts_102754v010201p.pdf

[35] A. Vena, E. Perret, and S. Tedjini, "Design rules for chipless RFID tags based on multiple scatterers," Ann. Telecommun., vol. 68, pp. 361-374, Aug. 2013.

[36] Code 39 barcode from Wikipedia. (2015) [Online]. Available: http://en.wikipedia.org/wiki/Code_39

[37] Pyralux AP Copper Clad substrate (2015) [Online]. Available: http://www2.dupont.com/Pyralux/en_US/products/laminate/AP/pyralux ap.html

[38] A. Muchkaev, "Carrierless RFID system," U.S. Patent 20070247311 A1, Oct. 25, 2008.

[39] A. Vena, E. Perret, and S. Tedjini, "A Depolarizing Chipless RFID Tag for Robust Detection and Its FCC Compliant UWB Reading System," IEEE Trans. Microw. Theory Techn., vol. 61, no. 8, pp. 2982 - 2994, 2013. 